ORIGINAL ARTICLE

\title{
Pegylated-asparaginase during induction therapy for adult acute lymphoblastic leukaemia: toxicity data from the UKALL14 trial
}

\author{
B Patel ${ }^{1}$, AA Kirkwood ${ }^{2}$, A Dey $^{3}$, DI Marks ${ }^{4}$ AK McMillan ${ }^{5}$, TF Menne ${ }^{6}$, L Micklewright ${ }^{2}$, P Patrick ${ }^{2}$, S Purnell $^{2}$, CJ Rowntree $^{7}$, \\ $P$ Smith ${ }^{2}$ and AK Fielding ${ }^{3}$
}

Safety and efficacy data on pegylated asparaginase (PEG-ASP) in adult acute lymphoblastic leukaemia (ALL) induction regimens are limited. The UK National Cancer Research Institute UKALL14 trial NCT01085617 prospectively evaluated the tolerability of 1000 IU/ $\mathrm{m}^{2}$ PEG-ASP administered on days 4 and 18 as part of a five-drug induction regimen in adults aged 25-65 years with de novo ALL. Median age was 46.5 years. Sixteen of the 90 patients (median age 56 years) suffered treatment-related mortality during initial induction therapy. Eight of the 16 died of sepsis in combination with hepatotoxicity. Age and Philadelphia (Ph) status were independent variables predicting induction death $>40$ versus $\leqslant 40$ years, odds ratio (OR) $18.5(2.02-169.0), P=0.01 ; \mathrm{Ph}-$ versus $\mathrm{Ph}+$ disease, OR 13.60 (3.52-52.36), $P<0.001$. Of the 74 patients who did not die, 37 (50.0\%) experienced at least one grade $3 / 4$ PEGASP-related adverse event, most commonly hepatotoxicity $(36.5 \%, n=27)$. A single dose of PEG-ASP achieved trough therapeutic enzyme levels in $42 / 49$ (86\%) of the patients tested. Although PEG-ASP delivered prolonged asparaginase activity in adults, it was difficult to administer safely as part of the UKALL14 intensive multiagent regimen to those aged $>40$ years. It proved extremely toxic in patients with $\mathrm{Ph}+\mathrm{ALL}$, possibly owing to interaction with imatinib.

Leukemia advance online publication, 9 September 2016; doi:10.1038/leu.2016.219

\section{INTRODUCTION}

Depletion of extracellular asparagine by parenteral administration of the enzyme L-asparaginase is a key component of most current therapeutic strategies in acute lymphoblastic leukaemia (ALL). In children, intensive L-asparaginase treatment, typically delivered by pegylated Escherichia coli-derived L-asparaginase (PEG-ASP), improves clinical outcome, ${ }^{1-6}$ offering a longer half-life ${ }^{7}$ and a lower risk of antiasparaginase antibody formation. Safety and efficacy is less well established in older adults, ${ }^{8,9}$ and toxicity can be substantial ${ }^{10}$-in a phase 2 trial, failure to deliver the intended doses was closely correlated with advancing age. ${ }^{11}$

UKALL14 (NCT01085617) is an on-going, multicentre, phase 3 study that addresses several questions in the treatment of newly diagnosed adult ALL. A major study aim is to evaluate the addition of two doses of $1000 \mathrm{IU} / \mathrm{m}^{2} \mathrm{PEG}$-ASP to the standard induction regimen that had been evaluated in our previous study, UKALL $12,{ }^{12}$ in which non-pegylated $E$. coli L-asparaginase was given at $10000 \mathrm{IU}$ daily on days $17-28$ of phase 1 induction. The only other change to the 'backbone' induction regimen between the two consecutive national trials was the addition of a steroid prephase and the substitution of pulsed dexamethasone for prednisolone. The aim of these changes was to make our regimen more compatible with a 'paediatric-inspired' intensive approach.

The overall end point of the trial is event-free survival. However, a specific end point of the PEG-ASP evaluation is toxicity related to PEG-ASP. Secondary end points include rate of complete remission (CR), overall survival, minimal residual disease (MRD) quantitation at the end of the first phase of induction and antiasparaginase antibody formation. Here we report on the outcome of PEG-ASP administered during induction in the first consecutive 91 trial subjects. At this point, it was judged by the trial management group that a toxicity end point had been reached and a change was made to the PEG-ASP trial therapy.

\section{MATERIALS AND METHODS}

UKALL14 induction phase 1 treatment

Eligible patients were aged $\geqslant 25$ and $\leqslant 65$ years with newly diagnosed ALL, irrespective of Philadelphia (Ph) chromosome status. There was no exclusion for poor organ function or performance status at diagnosis. Ethical approval was obtained from the UK National Research Ethics Committee. All patients gave written, informed consent, according to the Declaration of Helsinki. Patients received a 5-7-day prephase of dexamethasone $6 \mathrm{mg} / \mathrm{m}^{2} /$ day followed by two sequential courses of induction therapy, termed induction phase 1 and induction phase 2, respectively. Patients with precursor $B$ lineage ALL were randomised to receive chemotherapy alone or chemotherapy plus four doses of rituximab given on day (D) 3, D10, D17 and D24, PEG-ASP $1000 \mathrm{IU} / \mathrm{m}^{2}$ on D4 and D18, daunorubicin $60 \mathrm{mg} / \mathrm{m}^{2}$ and vincristine $1.4 \mathrm{mg} / \mathrm{m}^{2}$ (2 mg max.) on D1, D8, D15 and D21, dexamethasone $10 \mathrm{mg} / \mathrm{m}^{2} \mathrm{D} 1$, - D4, D8-D11 and D15-D18 and a single $12.5 \mathrm{mg}$ intrathecal methotrexate dose on D14. Patients with $\mathrm{Ph}$ chromosome-positive $(\mathrm{Ph}+)$ disease received continuous oral imatinib from D1, starting at $400 \mathrm{mg}$ and

\footnotetext{
${ }^{1}$ Barts Cancer Institute, The London School of Medicine, Queen Mary University of London, London, UK; ${ }^{2} \mathrm{CR}$ UK and UCL Cancer Trials Centre, London, UK; ${ }^{3}$ Cancer Institute, University College London, London, UK; ${ }^{4}$ Centre for Clinical Haematology, Nottingham City Hospital, Nottingham, UK; ${ }^{5}$ United Bristol Healthcare Trust, Bristol, UK; ${ }^{6}$ Newcastle Upon Tyne Hospitals NHS Foundation Trust, Newcastle Upon Tyne, UK and ${ }^{7}$ Cardiff and Vale UHB, London, UK. Correspondence: Professor AK Fielding, Cancer Institute, University College London, 72 Huntley Street, London WC1E 6DD, UK.

E-mail a.fielding@ucl.ac.uk

Received 22 April 2016; revised 6 July 2016; accepted 8 July 2016; accepted article preview online 2 August 2016
} 


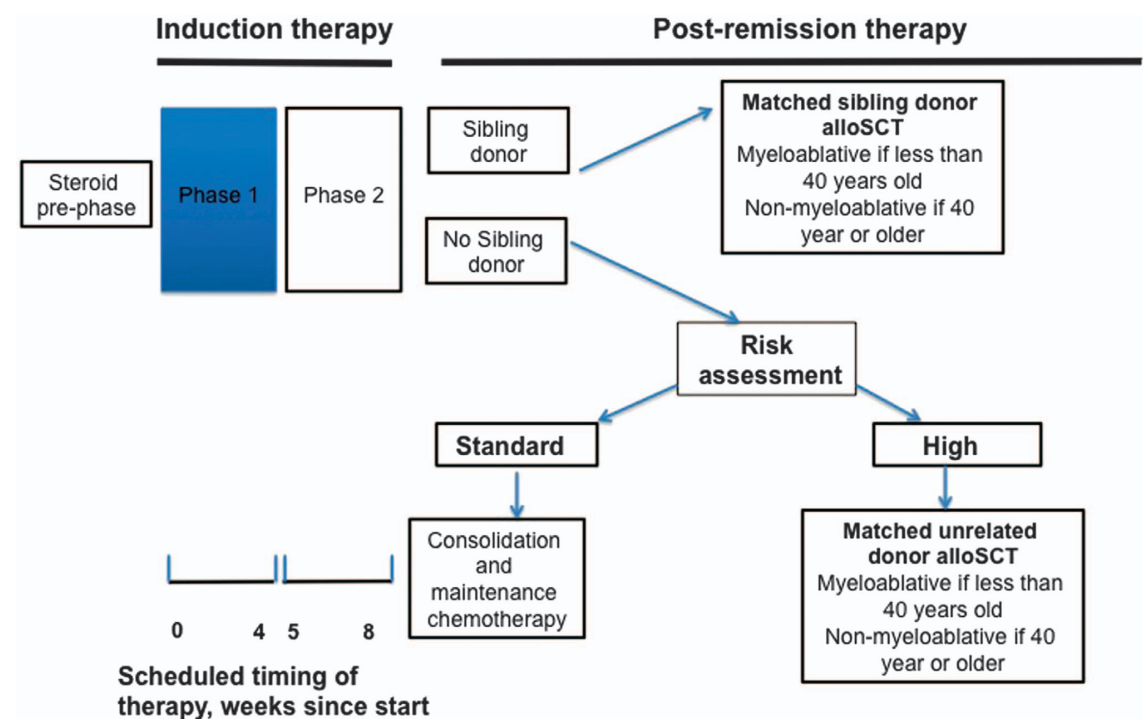

Figure 1. Schematic of UKALL14 treatment protocol. High risk features: karyotypes: $t(9 ; 22) t(4 ; 11)$, low hypodiploidy near triploidy or complex, age $>40$ years, WBC $\geqslant 30 \times 10^{9} /$ I (precursor $B$ lineage ALL), $\geqslant 100 \times 10^{9} /$ l (T-cell-ALL), molecular minimal residual disease positivity $\left(>1 \times 10^{-4}\right.$ ) after induction phase 2 .

escalating to $600 \mathrm{mg}$ given daily throughout induction. Antibacterial, antiviral and antifungal prophylaxis was mandated, but centres used local policy for choice of agents. Granulocyte colony-stimulating factor support was strongly recommended. Routine antithrombotic prophylaxis was suggested but not mandated for all patients with platelet counts $>50 \times 10^{9} /$. Anticoagulation with antithrombin replacement was recommended in the case of thrombosis. Routine coagulation factor replacement for laboratory-detected coagulopathy was specifically discouraged.

All patients had an initial assessment of response-including MRD response by $B C R-A B L$ transcript monitoring or clonal immunoglobulin (lg)/T-cell receptor gene rearrangement quantification-at the end of induction phase 1, which did not affect treatment decision. Formal assessment of response to induction therapy (outside the scope of this report) was documented after phase 2 induction.

A simplified schema of the remainder of UKALL14 treatment is provided in Figure 1.

\section{Causality assessment for toxicity and death}

The standard Common Terminology Criteria for Adverse Events (CTCAE) reporting system (http://ctep.cancer.gov/protocolDevelopment/electronic applications/ctc.htm) was used. Causality of events was attributed, as is standard practice, by both the local site Principal Investigator and the central study clinical team. Additional detailed questionnaires and Principal Investigator's narratives were received for all induction deaths allowing a more detailed analysis of individual events.

\section{PEG-ASP antibody assays}

Antibodies against PEG-ASP (IgG and IgE) were measured by two indirect enzyme-linked immunosorbent assays, which detected anti-PEG-ASP and non-pegylated anti-E. coli (non-pegylated asparaginase). Seroconversion was reported with positivity in at least one assay with a clearly negative predose sample. Anti-asparaginase antibody ratio over negative control $>1.1$ was used to define positivity.

Serum asparaginase activity by MAAT testing

PEG-ASP enzyme activity was quantified in sera using the MAAT ${ }^{7}$ assay. Therapeutic enzyme levels were defined as $>100 \mathrm{IU} / \mathrm{l}$.

Statistical analysis

Induction phase 1 treatment-related death was defined as any death occurring before the start of phase 2 induction where the cause of death was not primarily attributable to progressive ALL. Logistic regression was used to examine risk potential factors for induction death and grade $3 / 4$ adverse events (AEs). Factors with a conservative $P<0.2$ in the univariate analysis were included in the multivariable analyses. All analyses were conducted using Stata 14.0 (Stata Corporation, College Station, TX, USA). Non-fatal grade III-IV AEs causally related to PEG-ASP were those classified as probably or definitely related. All AEs were graded according to CTCAE version 4.0.

\section{RESULTS}

Patient characteristics

Ninety-one eligible patients (from 37 centres) were enrolled onto UKALL14 between 30 December 2010 and 19 April 2012. One patient died before starting any treatment and has been excluded from all analyses. Patient characteristics at diagnosis are summarised in Table 1 . The majority (59 of $90,66 \%$ ) of patients were aged $>40$ years and nearly a third $(26 / 90,29 \%)$ had Ph+ ALL. Most patients (92\%) had performance scores of $0-1$ at diagnosis. Median follow-up was 36.0 months (12 days50.4 months).

\section{Induction deaths}

Progress through the induction therapy blocks is shown in Figure 2. Among those commencing phase 1 induction therapy $(n=90)$, there were 18 early deaths. Two patients died of progressive ALL and the other $16(16 / 90,18 \%)$ deaths were related to induction treatment, occurring at a median time from start to induction of 23 days (range 10-53).

The causes of induction deaths are summarised in Table 2. In 12 of the $16(75 \%)$, the causes of death were most often multifactorial; sepsis together with hepatotoxicity occurred in 8 of 16, $50.0 \%$. Neutropenic sepsis alone occurred in 3 of the 16 patients, (18.8\%). A causative organism was identified in 11 of the cases of sepsis, with a Gram-negative bacterial infection being responsible in 8 of those. Additional causes of death were: hepatotoxicity plus bowel ischaemia $(n=2)$, acute coronary syndrome plus neutropenic sepsis $(n=1)$, hepatotoxicity plus pancreatitis $(n=1)$, and pulmonary haemorrhage $(n=1)$. Nine of the 11 hepatotoxicityrelated induction deaths were associated with grade 3-4 hyperbilirubinaemia. In total, half of the induction deaths were accompanied by recognised PEG-ASP toxicities (namely, those 
Table 1. Patient characteristics at diagnosis

\begin{tabular}{|c|c|}
\hline Characteristic & $\mathrm{N}(\%)$ \\
\hline \multicolumn{2}{|l|}{ Lineage } \\
\hline B-precursor & $77(86)$ \\
\hline T-cell & $13(14)$ \\
\hline \multicolumn{2}{|l|}{$\operatorname{Sex}$} \\
\hline Male & $48(53)$ \\
\hline Female & $42(47)$ \\
\hline \multicolumn{2}{|l|}{ Age at entry (years) } \\
\hline Median (range) & $46.50(25-65)$ \\
\hline$\geqslant 55$ & $29(32)$ \\
\hline$\geqslant 41$ & $59(66)$ \\
\hline \multicolumn{2}{|l|}{ Presenting WBC $\left(\times 10^{9} / \mathrm{I}\right)$} \\
\hline Median (range) & $9.26(0.52-297.4)$ \\
\hline$<30$ & $62(69)$ \\
\hline 30-99.9 & $15(17)$ \\
\hline $100+$ & $13(14)$ \\
\hline \multicolumn{2}{|l|}{ Cytogenetic risk status } \\
\hline High risk $^{\mathrm{a}}$ & $28(31)$ \\
\hline Low risk & $42(47)$ \\
\hline Unknown ${ }^{\mathrm{b}}$ & $20(22)$ \\
\hline \multicolumn{2}{|l|}{$t(9 ; 22)$} \\
\hline Absent & $64(71)$ \\
\hline Present & $26(29)$ \\
\hline \multicolumn{2}{|c|}{ Low hypodiploidy/near triploidy } \\
\hline Absent & $65(72)$ \\
\hline Present & $4(4)$ \\
\hline Failed/missing & $21(23)$ \\
\hline \multicolumn{2}{|l|}{$t(4 ; 11)$} \\
\hline Absent & $75(83)$ \\
\hline Present & $7(8)$ \\
\hline Failed/missing & $8(9)$ \\
\hline \multicolumn{2}{|l|}{ Complex karyotype } \\
\hline Absent & $64(71)$ \\
\hline Present & $5(6)$ \\
\hline Failed/missing & $21(23)$ \\
\hline \multicolumn{2}{|l|}{ Performance status } \\
\hline 0 & $55(61)$ \\
\hline 1 & $28(31)$ \\
\hline 2 & $5(6)$ \\
\hline 3 & $1(1)$ \\
\hline Missing & $1(1)$ \\
\hline \multicolumn{2}{|l|}{$B M I$} \\
\hline Normal/underweight ${ }^{c}$ & 31 (34) \\
\hline Overweight & $25(28)$ \\
\hline Obese & $34(38)$ \\
\hline
\end{tabular}

Abbreviations: BMI, body mass index; WBC, white blood cell. ${ }^{\text {HHigh risk: }}$ $\mathrm{t}(9 ; 22), \mathrm{t}(4 ; 11)$ low hypodiploidy/near triploidy or complex karyotypes. ${ }^{\mathrm{b}}$ No high-risk factors and at least one risk factor is missing or failed. ${ }^{\mathrm{C}} 30$ in the normal range and 1 patient with a BMI of 17 .

already listed in the Summary of Product Characteristics as occurring in $1: \geqslant 1000$ patients, or less common but clearly recognised as being related to PEG-ASP). There was no obvious association between baseline comorbidities and induction death.

All patients received D4 PEG-ASP. Sixty-four, including 5 of the 16 who suffered induction deaths, received the second dose on D18. For patients who died during induction, the median time from last dose of PEG-ASP to death was 13 days (range 6-50).

Risk factors for induction death

Table 3 shows a univariate analysis of factors predictive of induction death. Age, Ph positivity and high-risk cytogenetics were all risk factors. Patients aged over 40 years had a more than 10 -fold increase in risk of death during induction with $\mathrm{Ph}+$ disease conferring a more than 8-fold increase compared with $\mathrm{Ph}$ - disease (odds ratio (OR): 8.65 (2.61-28.71), $P<0.001)$. There was no relationship to baseline albumin levels or body mass index (BMI). The data monitoring committee also confirmed that there was no relationship to rituximab randomisation arm. The multivariable analysis is also shown in Table 3. Although high-risk cytogenetics appeared to be associated with induction death, this was driven by the presence of $t(9 ; 22)$, so this factor alone was included in the multivariable analysis. Age and $\mathrm{Ph}$ status remained significantly associated with induction death; in patients who were $\mathrm{Ph}-$, there were no deaths in the 21 patients aged $\leqslant 40$ years and 5 in the 43 patients aged $>40$ years. In patients with Ph+ ALL, 1 of the 10 patients aged $\leqslant 40$ years died compared with 10 of the 16 who were aged $>40$ years.

AEs during phase 1 induction therapy

Including the patients discussed above who subsequently died, 87 of the 91 patients (97\%) experienced a grade 3-5 AE during induction phase 1 ; among these 46 (51\%) suffered one or more recognised PEG-ASP toxicities; 34 had grade 3-5 AEs indicating liver dysfunction, including 22 with raised bilirubin. Other PEG-ASP toxicities included pancreatitis $(n=3)$, intracranial haemorrhage $(n=1)$, allergic reaction $(n=3)$, coagulation disorder $(n=4)$ and vascular events $(n=6)$. Thirty-seven of the 74 surviving patients $(50.0 \%)$ experienced at least one recognised grade 3-4 PEG-ASP-related, non-fatal toxicity summarised in Table 4. Hepatotoxicity-including biochemical markers of liver dysfunction-was the most frequent PEG-ASP-related toxicity $(36.5 \%, n=27)$. Venous thromboembolism $(4.1 \%, n=3)$, allergic reaction $(4.1 \%, n=3)$ and pancreatitis $(2.7 \%, n=2)$ were all reported but were relatively uncommon. A complete line-listing of all $A E$ /serious $A E$ as well as the subset known to be recognised toxicities of PEG-ASP from which Table 4 is derived is given in Supplementary Supplementary Table S1. As liver toxicity was so prominent and can be a key determinant of subsequent on-time therapy delivery, an analysis of any pretreatment factors associated with grade 3-4 hepatotoxicity was carried out. This is shown in Table 5 . Older age and BMI were the only factors that showed a significant association (OR: 2.88 (1.62-15.44), $P=0.005$, for patients aged $>40$ years compared with those $\leqslant 40$ years and OR: 1.58 (1.02-2.44), $P=0.041$, for a 5 unit increase in BMI).

Asparaginase activity, antiasparaginase antibody formation and correlation with MRD response

A trough level of asparaginase activity by MAAT testing ${ }^{7,13}$ was assessed 14 days after the first (D4) PEG-ASP dose in 49 patients in whom serum was available $(n=49)$. Therapeutic activity (enzyme level $>100 \mathrm{IU} / \mathrm{I})$ was achieved in 42 of 49 (86\%). The median enzyme level in those achieving therapeutic enzyme levels was $234 \mathrm{IU} / \mathrm{I}$ (range 101.5-602.8) as compared with 44.8IU/I (0-97.5) in those with subtherapeutic levels. There was no evidence of an association between age and achievement of therapeutic enzyme level. Molecular MRD at the end of phase 1 induction was documented in 27 patients. Molecular remission rates did not significantly differ between those achieving therapeutic enzyme levels of PEG-ASP and those who did not (14/26 compared with 


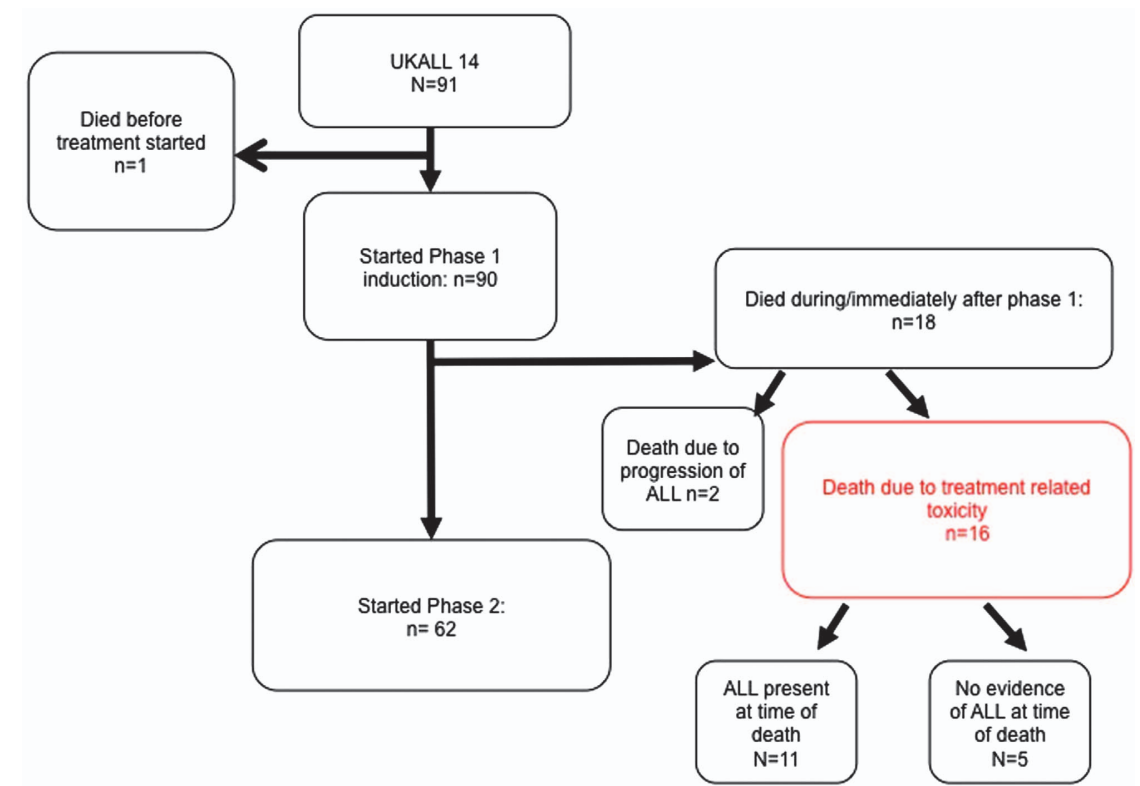

Figure 2. Flow chart of progress of the 91 patients enrolled. Grade 4 sepsis $n=4$, grade IV organ toxicity $n=4$ (hepatotoxicity $n=1$, pancreatitis $n=1$, hepatotoxicity plus neurological event $n=1$, hepatotoxicity plus thromboembolism together with sepsis $n=1$ and wrong diagnosis $n=1$, withdrawal of consent, $n=1$.

\begin{tabular}{|c|c|c|c|c|c|c|c|c|c|c|}
\hline 1003 & Age 54 years $\mathrm{PH}-$ & $\begin{array}{l}\text { Liver } \\
\text { cirrhosis }\end{array}$ & 4 & Not known & & & & & D4 and 18 & 19 \\
\hline 1004 & Age 46 years $\mathrm{PH}+$ & None & & $\begin{array}{l}\text { Pseudomonas } \\
\text { aeruginosa }\end{array}$ & & $\begin{array}{l}\text { Acute coronary } \\
\text { syndrome }\end{array}$ & & & D4 & 16 \\
\hline 1026 & Age 64 years $\mathrm{PH}+$ & Depression & 4 & $\begin{array}{l}\text { Pseudomonas } \\
\text { aeruginosa }\end{array}$ & & & & & D4 & 20 \\
\hline 1028 & Age 38 years $\mathrm{PH}+$ & None & & Enterococcus faecium & & & & & D4 & 15 \\
\hline 1029 & Age 60 years $\mathrm{PH}+$ & $\mathrm{IHD}$ & 4 & Escherichia coli & & & & & D4 & 14 \\
\hline 1030 & Age 49 years $\mathrm{PH}+$ & None & & & Pulmonary & & & & D4 & 6 \\
\hline 1039 & Age 62 years $\mathrm{PH}+$ & None & 2 & & & Small bowel & & & D4 & 10 \\
\hline 1061 & Age 54 years $\mathrm{PH}+$ & $\begin{array}{l}\text { Paroxysmal } \\
\text { atrial } \\
\text { fibrillation }\end{array}$ & 3 & & & & Yes & Gl perforation & D4 & 10 \\
\hline 1063 & Age 62 years $\mathrm{PH}+$ & None & & $\begin{array}{l}\text { Coagulase-negative } \\
\text { staph/Enterococcus } \\
\text { faecium }\end{array}$ & & & & & D4 and D18 & 12 \\
\hline 1068 & Age 64 years $\mathrm{PH}+$ & None & 4 & $\begin{array}{l}\text { Respiratory syncytial } \\
\text { virus }\end{array}$ & & & & Renal failure & D4 & 21 \\
\hline 2007 & Age 55 years $\mathrm{PH}-$ & None & & $\begin{array}{l}\text { Pseudomonas } \\
\text { aeruginosa }\end{array}$ & & & & & D4 and D18 & 8 \\
\hline
\end{tabular}

3/4), suggesting that an early complete molecular response in this setting is not contingent upon therapeutic asparaginase enzyme activity. Anti-PEG-ASP antibody formation at D18 was assessed in 59 patients, and at that time point, there were no instances of seroconversion.

\section{DISCUSSION}

Successful achievement of CR during induction therapy for ALL is an absolute prerequisite for long-term disease-free survival. Numerous previous studies have suggested that induction regimens typically used in children give a better 
Table 3. Univariate and multivariate analysis of risk factors for induction death

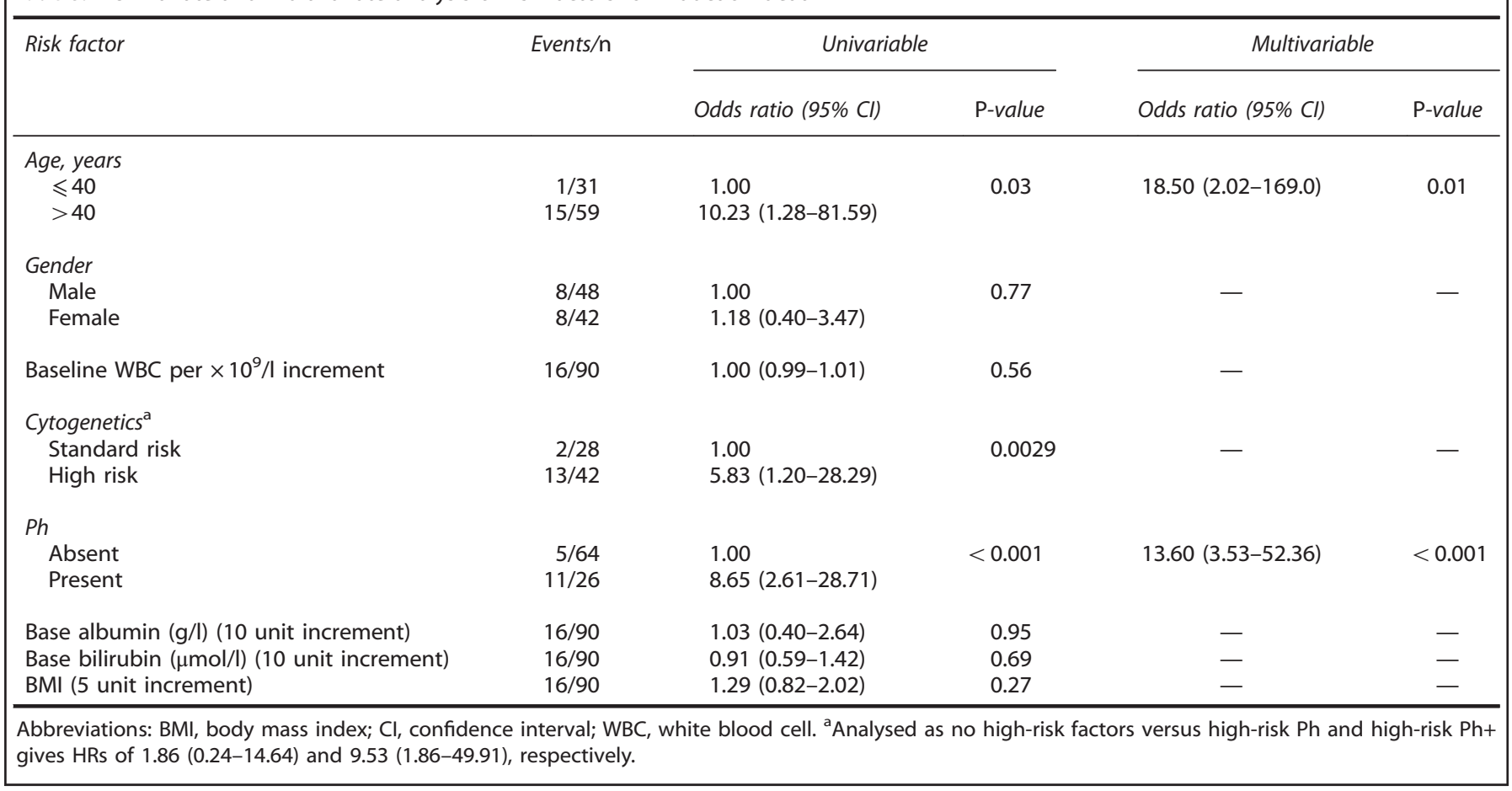

outcome for teenagers and younger adults than typical 'adult' regimens. ${ }^{14-18}$ As a consequence, there is general acceptance of testing the outcome of increasing the intensity of nonmyelosuppressive agents such as PEG-ASP in regimens used for older adults.

Within the first 91 patients enrolled, we noted significantly greater induction mortality in UKALL14 than in our previous trial, UKALL12. Induction death occurred in 16 of the first 90 (17.8\%) treated patients, and 15 of the first 59 (25\%) participants being aged $>40$ years (10/29 (33\%) being aged $>55$ years). The median age of the patient population enrolled in this period was 46.5 years, with $29 \%$ of patients being aged >55 years. By comparison, the induction death rate in our previous trial, UKALL12/ECOG2993, was 6\% overall (ages $15-60$ years, median age 36 years) ${ }^{12}$ and $15 \%$ in the 55-65-year range (median age 56 years). ${ }^{19}$ UKALL14 did not exclude any patient with poor organ function or comorbidity at diagnosis, but we did not find any evidence of these factors having a causal contribution to PEG-ASP-related mortality.

Analysis of the cause of each death in UKALL14 included a complete written narrative from the treating physician as well as the standard case report forms for serious AE collection. Bacterial sepsis was revealed as a major contributor to the deaths. However, concomitant grade 3-4 PEG-ASP toxicities were very common among those suffering induction death, such that a recognised PEG-ASP toxicity was associated with half of the 16 induction deaths. It is impossible to disentangle the role of the investigational medicinal product (IMP) PEG-ASP from that of concomitant non-IMP induction agents. However, the introduction of dexamethasone instead of prednisolone was the only change that had been made to the standard backbone regimen between UKALL12 and UKALL14.

It is noteworthy that most of the induction deaths reported here occurred after an early, single (D4) dose of PEG-ASP, any toxicity of which would overlap with the myelosuppressive toxicity of anthracycline administered on D1, D8, D15 and D22. The $60 \mathrm{mg} /$ $\mathrm{m}^{2}$ dose of anthracycline given in the UKALL12 regimen was well tolerated, but asparaginase was not started until D17. The earlier addition of PEG-ASP-associated liver dysfunction to subsequent myelosuppression-related sepsis may have been responsible for the overlapping toxicity. The fact that sepsis was a major contributor to the mortality supports that contention.

To date, only two other studies reporting the use of PEG-ASP specifically in adults have been published, both of which report a lower dose and/or different schedule of anthracycline. A phase 2 trial CALGB $9511^{\text {(ref. 11) }}$ reported on 102 adults treated with PEGASP at $2000 \mathrm{U} / \mathrm{m}^{2}$ subcutaneously, capped at $3750 \mathrm{U} / \mathrm{m}^{2}$, starting on D5 of the five-drug induction regimen. Although the regimen was reported to be 'tolerable', bilirubin $>51.3 \mu \mathrm{m}(3 \mathrm{mg} / \mathrm{dl})$ occurred in $54 \%$ of patients. CR rate was only $77 \%$ but induction deaths are not separated from induction failures within the report. There was a statistically significant difference in median age of those achieving full dose delivery and asparagine depletion-32 years versus 48 years. In a more recent study from Douer et al. ${ }^{20}$ in 51 adults median age 32 years, upper age limit 57 years reported no deaths directly as a result of PEG-ASP in regimen, which included $2000 \mathrm{lU} / \mathrm{m}^{2}$ PEG-ASP given on D15. However, 3 of the 51 (6\%) patients died of neutropenic sepsis during consolidation. In this case, daunorubicin was given at $60 \mathrm{mg} / \mathrm{m}^{2}$ intravenously on D1-D3. Grade 3-4 hyperbilirubinaemia (1/3 patients) or transaminitis (2/3 of patients) was very common. Douer et al. ${ }^{20}$ also reported long median intervals from PEG-ASP to bilirubin recovery, which affected subsequent chemotherapy delivery. The younger median age of patients in that study, the small number receiving concurrent imatinib $(N=5)$, a more modest anthracycline dose and different scheduling of PEG-ASP administration so as not to coincide with the maximal myelosuppression may all have contributed to the difference in toxicity.

The German Multicentre Adult ALL Group have reported in abstract form ${ }^{21}$ on 1000 adult patients aged $15-55$ years, treated on the German 07/2003 study in which a single dose of 1000 $2000 \mathrm{U} / \mathrm{m}^{2}$ PEG-ASP was administered on D3 during induction with a reported rate of induction death rate of $<5 \%$ and a grade IV hyperbilirubinaemia incidence of $16 \%$. As with the study by Douer et al., ${ }^{20}$ the younger median age (35 years) of the cohort in addition to the lower dose of anthracycline (45 versus the $60 \mathrm{mg} / \mathrm{m}^{2}$ used in the current study) may underpin the differences in toxicity. 
Table 4. Patients who did not die during induction: summary of the grade $3 / 4$ AEs recognised in SPC as being related to PEG-ASP ${ }^{a}$

\begin{tabular}{lc}
\hline SOC/event term & Grade $3+$ PEG-ASP known AEs, \\
& $\mathrm{N}(\%)$ \\
\hline Gastrointestinal disorders & $2(3)$ \\
Pancreatitis & $2(3)$ \\
& \\
Hepatobiliary disorders & $3(4)$ \\
Liver failure & $1(1)$ \\
Liver dysfunction & $2(3)$ \\
Immune system disorders & $3(4)$ \\
Allergic reaction & $3(4)$ \\
Investigations & $29(39)$ \\
Lipase increased & $1(1)$ \\
Serum amylase increased & $3(4)$ \\
Alkaline phosphatase increased & $15(20)$ \\
Aspartate aminotransferase & $4(5)$ \\
increased & $17(23)$ \\
Blood bilirubin increased & $10(14)$ \\
Alanine aminotransferase & \\
increased & $5(7)$ \\
GGT increased & $3(4)$ \\
Metabolism and nutrition disorders & $1(1)$ \\
Increased triglycerides & $2(3)$ \\
Hypoalbuminaemia & $1(1)$ \\
Nervous system disorders & $1(1)$ \\
Intracranial haemorrhage & \\
Vascular disorders & $4(5)$ \\
Pulmonary embolism & $1(1)$ \\
Thromboembolic event & $3(4)$ \\
Non-CTCAE terms & \\
Coagulation disorder & $37(50)$ \\
Any liver event & \\
Any toxicity & \\
\hline Abbreviations: AE, adverse event; CTCAE, Common & Terminology Criteria; \\
GGT, gamma glutamyl transpeptidase; PEG-ASP, pegylated asparaginase; \\
SPC, Summary of Product Characteristics; SOC, System Organ Class. \\
a complete line listing of grade 3+ AE/serious AE according to CTCAE \\
criteria with assignment of causality by both site and by trial management \\
group is provided in Supplementary Table S1. \\
\hline
\end{tabular}

It should be noted that the French GRAAALL group also reported that advancing age resulted in a higher cumulative incidence of chemotherapy-related deaths (23\% versus $5 \%$, respectively; $P<0.001)$ and deaths in first CR $(22 \%$ versus $5 \%$, respectively; $P<0.001)$ during 'paediatric-style' therapy, even when non-pegylated asparaginsae was used. In the study reported by Huguet et al., ${ }^{22} \geqslant 45$ years of age was the strongest predictor of severe toxicity,

As a consequence of the toxicity reported here, the UKALL14 protocol was amended to omit D4 PEG-ASP for those aged $>40$ years. Furthermore, PEG-ASP was completely removed from induction treatment for all patients with $\mathrm{Ph}+\mathrm{ALL}$. In addition, owing to the high level of sepsis related to profound myelosuppression, the daunorubicin dose was halved to $30 \mathrm{mg} / \mathrm{m}^{2}$ on D1, D8, D15 and D22. One year following this amendment, when an additional 302 further patients had been recruited with 244 patients assessable for induction death, a repeat analysis showed only $6(2.5 \%)$ phase 1 induction deaths (data not shown).

Univariate analysis demonstrated that older age and poor-risk cytogenetics -including $t(9 ; 22)$-were significantly associated with induction death. On multivariable analysis, age and $\mathrm{Ph}$ positivity remained as independent risk factors for induction
Table 5. Analysis of risk factors for liver-related grade $3 / 4$ adverse events during phase 1 induction in patients who did not have an induction death

\begin{tabular}{|c|c|c|c|}
\hline \multirow[t]{2}{*}{ Risk factor } & \multicolumn{3}{|c|}{ Grade 3/4 liver AEs } \\
\hline & Events/n & $\begin{array}{l}\text { Odds ratio } \\
(95 \% \mathrm{Cl})\end{array}$ & P-value \\
\hline \multicolumn{4}{|l|}{ Age } \\
\hline$\leqslant 40$ & $5 / 30$ & 1.00 & 0.005 \\
\hline$>40$ & $22 / 44$ & $2.9(1.62-15.44)$ & \\
\hline \multicolumn{4}{|l|}{ Sex } \\
\hline Male & $16 / 40$ & 1.00 & 0.50 \\
\hline Female & $11 / 34$ & $0.72(0.28-1.87)$ & \\
\hline $\begin{array}{l}\text { Baseline WBC per } \times 10^{9} / / \\
\text { increment }\end{array}$ & $27 / 74$ & $1.00(0.99-1.01)$ & 0.71 \\
\hline \multicolumn{4}{|l|}{ Cytogenetics } \\
\hline Standard risk & $10 / 26$ & 1.00 & 0.97 \\
\hline High risk & $11 / 29$ & $0.98(0.33-2.91)$ & \\
\hline \multicolumn{4}{|l|}{$\mathrm{Ph}$} \\
\hline Absent & $20 / 59$ & 1.00 & 0.36 \\
\hline Present & $7 / 15$ & $1.71(0.54-5.38)$ & \\
\hline $\begin{array}{l}\text { Base albumin (g/l) (10 unit } \\
\text { increment) }\end{array}$ & $27 / 74$ & $0.89(0.41-1.92)$ & 0.77 \\
\hline $\begin{array}{l}\text { Base bilirubin ( } \mu \mathrm{mol} / \mathrm{l}) \text { (10 unit } \\
\text { increment) }\end{array}$ & $27 / 74$ & $1.02(0.81-1.30)$ & 0.86 \\
\hline BMI (5 unit increment) & $27 / 74$ & $1.58(1.02-2.44)$ & 0.041 \\
\hline
\end{tabular}

Abbreviations: $\mathrm{AE}$, adverse event; $\mathrm{BMI}$, body mass index; $\mathrm{Cl}$, confidence interval; WBC, white blood cell.

death, suggesting that the concomitant imatinib therapy only received by those with $\mathrm{Ph}+\mathrm{ALL}$ may have compounded the potential for PEG-ASP toxicity. The precise mechanism by which this might occur is not known. However, from the Summary of Product Characteristics for imatinib, 'increased hepatic enzymes' is reported as common (1:10 to 1:100), hyperbilirubinaemia occurs in between 1:100 and 1:1000 patients and, finally, hepatic failure is noted as 'rare', namely, occurring between 1:1000 and 1:10 000 cases. Hence, the potential for overlapping hepatotoxicity of PEGASP and imatinib is clearly present.

Half of the patients who did not experience an induction death experienced one or more grade 3-4 PEG-ASP toxicities from which they eventually recovered-most commonly, hepatotoxicity. Twenty-three percent of patients in this study experienced grade $\geqslant 3$ hyperbilirubinaemia; by definition, a limitation or exclusion to further dosing with many commonly used ALL therapeutics. On analysis of treatment delays in our previous trial, UKALL12/E2993 study showed that delays of $>4$ weeks were associated with poorer overall survival and event-free survival in patients undergoing allogeneic hematopoietic stem cell transplantation but not in patients undergoing postremission chemotherapy. ${ }^{22}$ Any longterm impact of any delays engendered by toxicity during initial induction therapy in this study will become clear when the trial is completed and we can evaluate any delays in relation to our primary end point, event-free survival.

Our pharmacokinetic studies indicate that a single dose of $1000 \mathrm{lU} / \mathrm{m}^{2}$ PEG-ASP generates therapeutic enzyme levels in most patients $-86 \%$ of assessable patients had therapeutic levels of PEG-ASP activity 14 days after administration. A recent longitudinal analysis of PEG-ASP pharmacokinetics during a 'paediatric' regimen in adult $A L L$ demonstrated therapeutic enzyme activity in a similar proportion of adult patients for up to 21 days. ${ }^{20}$ In our 
study, antiasparaginase antibodies were not seen at the early time point documented.

In conclusion, we have shown that PEG-ASP achieves very effective asparagine depletion without antiasparaginase antibody formation in the majority of adult patients. However, toxicity can be substantial in older patients, making a 'paediatric-inspired' regimen of the type commonly used used in paediatric and young adult therapy difficult to deliver safely to those aged $>40$ years. Avoidance of overlapping toxicities and careful timing of administration will be of key importance to the more widespread use of this type of regimen in older adults.

As remission can be induced with minimal mortality in patients with $\mathrm{Ph}+\mathrm{ALL}^{23,24}$ we suggest that PEG-ASP is never coadministered with imatinib during induction therapy.

\section{CONFLICT OF INTEREST}

Fielding received lab funding from Medac $\mathrm{GmBH}$ to carry out part of this work and that company were the supplier of PEG-ASP at the time of this work. The remaining authors declare no conflict of interest.

\section{ACKNOWLEDGEMENTS}

UKALL14 was funded by Cancer Research UK grant CRUK/09/006 to AKF. The MAAT testing and antiasparaginase antibody testing was funded by a 2-year, unrestricted educational grant from Medac GMBH to AKF between 2010 and 2012. BP was funded by Bloodwise grant 07062 . We thank all centres and patients who contributed to this study.

\section{AUTHOR CONTRIBUTIONS}

$B P, A K$ and AKF wrote the paper. AKF designed the study, contributed data and was Chief Investigator of the trial. AK analysed data. PS, LM, SP and PP co-ordinated the study, collected data and contributed to the analysis. AD carried out the MAAT testing. CJR, TM, AKMCM and DM contributed data and managed the trial. All authors contributed to writing the manuscript and approved the final version.

\section{REFERENCES}

1 Sallan SE, Hitchcock-Bryan S, Gelber R, Cassady JR, Frei E 3rd, Nathan DG. Influence of intensive asparaginase in the treatment of childhood non-T-cell acute lymphoblastic leukemia. Cancer Res 1983; 43: 5601-5607.

2 Avramis VI, Sencer S, Periclou AP, Sather H, Bostrom BC, Cohen LJ et al. A randomized comparison of native Escherichia coli asparaginase and polyethylene glycol conjugated asparaginase for treatment of children with newly diagnosed standard-risk acute lymphoblastic leukemia: a Children's Cancer Group study. Blood 2002; 99: 1986-1994.

3 Seibel NL. Treatment of acute lymphoblastic leukemia in children and adolescents: peaks and pitfalls. Hematology Am Soc Hematol Educ Program 2008, 374-380.

4 Avramis VI, Spence SA. Clinical pharmacology of asparaginases in the United States: asparaginase population pharmacokinetic and pharmacodynamic (PK-PD) models (NONMEM) in adult and pediatric ALL patients. J Pediatr Hematol Oncol 2007; 29: 239-247.

5 Kurtzberg J, Asselin B, Bernstein M, Buchanan GR, Pollock BH, Camitta BM. Polyethylene glycol-conjugated $\mathrm{L}$-asparaginase versus native $\mathrm{L}$-asparaginase in combination with standard agents for children with acute lymphoblastic leukemia in second bone marrow relapse: a Children's Oncology Group Study (POG 8866). J Pediatr Hematol Oncol 2011; 33: 610-616.

6 Pession A, Valsecchi MG, Masera G, Kamps WA, Magyarosy E, Rizzari C et al. Long-term results of a randomized trial on extended use of high dose L-asparaginase for standard risk childhood acute lymphoblastic leukemia. J Clin Oncol 2005; 23: 7161-7167.

7 Asselin BL, Whitin JC, Coppola DJ, Rupp IP, Sallan SE, Cohen HJ. Comparative pharmacokinetic studies of three asparaginase preparations. J Clin Oncol 1993; 11: 1780-1786.

8 Douer D. Is asparaginase a critical component in the treatment of acute lymphoblastic leukemia? Best Pract Res Clin Haematol 2008; 21: 647-658.

9 Douer D, Yampolsky H, Cohen LJ, Watkins K, Levine AM, Periclou AP et al. Pharmacodynamics and safety of intravenous pegaspargase during remission induction in adults aged 55 years or younger with newly diagnosed acute lymphoblastic leukemia. Blood 2007; 109: 2744-2750.

10 Stock W, Douer D, Deangelo DJ, Arellano M, Advani A, Damon L et al. Prevention and management of asparaginase/pegasparaginase-associated toxicities in adults and older adolescents: recommendations of an expert panel. Leuk Lymphoma 2011; 52: 2237-2253.

11 Wetzler M, Sanford BL, Kurtzberg J, Deoliveira D, Frankel SR, Powell BL et al. Effective asparagine depletion with pegylated asparaginase results in improved outcomes in adult acute lymphoblastic leukemia -- Cancer and Leukemia Group B Study 9511. Blood 2007; 109: 4164-4167.

12 Rowe JM, Buck G, Burnett AK, Chopra R, Wiernik PH, Richards SM et al. Induction therapy for adults with acute lymphoblastic leukemia: results of more than 1500 patients from the international ALL trial: MRC UKALL XII/ECOG E2993. Blood 2005; 106: 3760-3767.

13 Fabry U, Korholz D, Jurgens H, Gobel U, Wahn V. Anaphylaxis to L-asparaginase during treatment for acute lymphoblastic leukemia in children--evidence of a complement-mediated mechanism. Pediatr Res 1985; 19: 400-408.

14 DeAngelo DJ, Stevenson KE, Dahlberg SE, Silverman LB, Couban S, Supko JG et al. Long-term outcome of a pediatric-inspired regimen used for adults aged 18-50 years with newly diagnosed acute lymphoblastic leukemia. Leukemia 2015; 29: 526-534.

15 Boissel N, Auclerc MF, Lheritier V, Perel Y, Thomas X, Leblanc T et al. Should adolescents with acute lymphoblastic leukemia be treated as old children or young adults? Comparison of the French FRALLE-93 and LALA-94 trials. J Clin Oncol 2003; 21: 774-780.

16 de Bont JM, Holt B, Dekker AW, van der Does-van den Berg A, Sonneveld P, Pieters R. Significant difference in outcome for adolescents with acute lymphoblastic leukemia treated on pediatric vs adult protocols in the Netherlands. Leukemia 2004; 18: 2032-2035.

17 Ramanujachar R, Richards S, Hann I, Goldstone A, Mitchell C, Vora A et al. Adolescents with acute lymphoblastic leukaemia: outcome on UK national paediatric (ALL97) and adult (UKALLXII/E2993) trials. Pediatr Blood Cancer 2007; 48: 254-261.

18 Stock W, La M, Sanford B, Bloomfield C, Vardiman J, Gaynon P et al. What determines the outcomes for adolescents and young adults with acute lymphoblastic leukemia treated on cooperative group protocols? A comparison of Children's Cancer Group and Cancer and Leukemia Group B studies. Blood 2008; 112: $1646-1654$.

19 Sive Jl, Buck G, Fielding A, Lazarus HM, Litzow MR, Luger S et al. Outcomes in older adults with acute lymphoblastic leukaemia (ALL): results from the international MRC UKALL XII/ECOG2993 trial. Br J Haematol 2012; 157: 463-471.

20 Douer D, Aldoss I, Lunning MA, Burke PW, Ramezani L, Mark L et al. Pharmacokinetics-based integration of multiple doses of intravenous pegaspargase in a pediatric regimen for adults with newly diagnosed acute lymphoblastic leukemia. J Clin Oncol 2014; 32: 905-911.

21 Goekbuget N. PEG-asparaginase intensification in adult acute lymphoblastic leukemia (ALL): significant improvement of outcome with moderate increase of liver toxicity in the German Multicenter Study Group for Adult ALL (GMALL) Study 07/2003. ASH Annu Meeting Abstr 2010; 116: 494.

22 Huguet F, Leguay T, Raffoux E, Thomas X, Beldjord K, Delabesse E et al. Pediatric-inspired therapy in adults with Philadelphia chromosome-negative acute lymphoblastic leukemia: the GRAALL-2003 study. J Clin Oncol 2009; 27: 911-918.

23 Vignetti M, Fazi P, Cimino G, Martinelli G, Di Raimondo F, Ferrara F et al. Imatinib plus steroids induces complete remissions and prolonged survival in elderly Philadelphia chromosome-positive patients with acute lymphoblastic leukemia without additional chemotherapy: results of the Gruppo Italiano Malattie Ematologiche dell'Adulto (GIMEMA) LAL0201-B protocol. Blood 2007. 109: 3676-3678.

24 Foa R, Vitale A, Vignetti M, Meloni G, Guarini A, De Propris MS et al. Dasatinib as first-line treatment for adult patients with Philadelphia chromosome-positive acute lymphoblastic leukemia. Blood 2011; 118: 6521-6528.

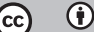

This work is licensed under a Creative Commons Attribution 4.0 International License. The images or other third party material in this article are included in the article's Creative Commons license, unless indicated otherwise in the credit line; if the material is not included under the Creative Commons license, users will need to obtain permission from the license holder to reproduce the material. To view a copy of this license, visit http://creativecommons.org/licenses/by/4.0/

(c) The Author(s) 2016

Supplementary Information accompanies this paper on the Leukemia website (http://www.nature.com/leu) 